\title{
Microstructure and Thermoelastic Martensitic Transformations in Ni-Mn-Al Based Alloys
}

\author{
Artemy V. Pushin ${ }^{1,2}$, Elena S. Belosludtseva ${ }^{1}$, Alexey E. Svirid ${ }^{1}$, and Vladimir G. \\ Pushin ${ }^{1,2}$ \\ ${ }^{1}$ M.N. Miheev Institute of Metal Physics of Ural Branch of Russian Academy of Sciences (IMP UB \\ RAS), 18 S. Kovalevskaya Street, Ekaterinburg, Russian Federation, 620108; \\ ${ }^{2}$ The First President of Russia B. N. Yeltsin Ural Federal University (UrFU); 19 Mira Street, \\ Ekaterinburg, 620002
}

\section{Abstract}

The physical properties and structure, thermoelastic martensitic transformations (TMT's) of $\mathrm{Ni}_{50} \mathrm{Mn}_{50-x} \mathrm{Al}_{x}$ alloys $(\mathrm{x}=0-25)$ were studied by the methods of resistomeyry and durametry, transmission and scaning electron microscopy (TEM and SEM), and X-ray diffraction analysis. It has been shown that the critical temperatures of TMT's are found to be decrease with increasing aluminum content, and the structure of martensite

Corresponding Author:

Artemy V. Pushin

avpushin@rambler.ru

Received: 25 February 2019

Accepted: 9 April 2019

Published: 15 April 2019

Publishing services provided by

Knowledge E

(c) Artemy V. Pushin et al. This article is distributed under the terms of the Creative Commons

Attribution License, which permits unrestricted use and redistribution provided that the original author and source are credited.

Selection and Peer-review under the responsibility of The Ural school-seminar of metal scientists-young researchers Conference Committee.

\section{G OPEN ACCESS} changes: $2 \mathrm{M}\left(\mathrm{L} 1_{0}\right)$ and multilayered $10 \mathrm{M}$ and $14 \mathrm{M}$. Martensite has a hierarchic packet morphology of coherent plates of nano- and submicrocrystalline crystals with habit boundaries close to $\{110\}_{B 2}$.

Keywords: thermoelastic martensitic transformations, phase composition, Ni-Mn, martensite, electron-microscopic studies.

\section{Introduction}

The thermoelastic $\mathrm{B} 2 \leftrightarrow \mathrm{L} 1_{0}$ martensitic transformations in binary $\mathrm{Ni}_{50} \mathrm{Mn}_{50}$ and $\mathrm{Ni}_{49} \mathrm{Mn}_{51}$ alloys are known to occur at high temperatures; therefore, it is rather difficult to study the structure and properties of these alloys. In [1, 2], we comprehensively investigated the fine structure and the TMTs of these alloys and determined critical temperatures: $\mathrm{M}_{s}$ $=970 \mathrm{~K}, \mathrm{M}_{f}=920 \mathrm{~K}, \mathrm{~A}_{s}=970 \mathrm{~K}$, and $\mathrm{A}_{f}=1020 \mathrm{~K} ; \mathrm{M}_{s}=940 \mathrm{~K}, \mathrm{M}_{f}=930 \mathrm{~K}, \mathrm{~A}_{s}=990$ $\mathrm{K}$, and $\mathrm{A}_{f}=1000 \mathrm{~K}$, respectively. The high temperature $\mathrm{B} 2 \leftrightarrow \mathrm{L} 1_{0}$ phase transformations were detected in many binary and multicomponent intermetallic alloys based on nickel and titanium, such as $\mathrm{Ni}-\mathrm{Mn}, \mathrm{Ni}-\mathrm{Mn}-\mathrm{Al}, \mathrm{Ni}-\mathrm{Al}, \mathrm{Ni}-\mathrm{Al}-\mathrm{Co}$, Ni-Cu-Al, Ti-Rh, Ti-Rh-Ni, $\mathrm{Ti}-\mathrm{Ir}$, and $\mathrm{Ti}-\mathrm{Ir}-\mathrm{Ni}$ [3-14]. We assumed that these transformations in the alloys based on these intermetallic compounds also has the character of TMT, which should cause shape memory effects in them. Nevertheless, the boundaries of phase transformations and the crystal-structure types of austenite and martensite phases have not been exactly determined for ternary $\mathrm{Ni}-\mathrm{Mn}-\mathrm{Al}$ quasi-binary system. As a rule, alloying with a third 
chemical element decreases critical temperatures $\mathrm{M}_{s}, \mathrm{M}_{f}, \mathrm{~A}_{s}$, and $\mathrm{A}_{f}$, which facilitates the designing of alloys with given martensitic transformation parameters. The purpose of this work is to study the influence of aluminum alloying on the structure and the thermoelastic martensitic transformations, i.e., the critical points of the forward $\left(\mathrm{M}_{s}, \mathrm{M}_{f}\right)$ and reverse $\left(\mathrm{A}_{s}, \mathrm{~A}_{f}\right)$ transformations, in quasi-binary $\mathrm{Ni}_{50} \mathrm{Mn}_{50-x} \mathrm{Al}_{x}$ alloys. There is reason to believe that this transformations in alloys based on such intermetallic compounds and in other B2 nonferrous alloys (titanium nickelide, copper based alloys, ferromagnetic Heusler alloys, alloys based on alloyed manganese nickelide) also have characteristics of TMT, and this fact should cause the shape memory effects in them.

\section{Materials and Methods}

The alloys were melted by the electric-arc method from high-purity metals $(99,99$ $99,999 \%$ purity) in an inert atmosphere of purified argon. The ingots (certified by the chemical composition) for homogenization were subjected to remelting (at least three times) followed by longterm vacuum annealing at $1173 \mathrm{~K}$. The alloy ingots were spark-cut into plates, which were again subjected to homogenizing annealing during $6 \mathrm{~h}$ followed by water quenching or slow $(\sim 100 \mathrm{~K} / \mathrm{h})$ cooling from 1073 or $1173 \mathrm{~K}$. The X-ray diffraction analysis by the $\theta / 2 \theta$ method was carried out using a DRON-3M diffractometer in the $\mathrm{Cu}$ $K \alpha$ radiation monochromatized by a graphite single crystal. The electron-microscopic studies were performed at the Center of Collaborative Access, Institute of Metal Physics, Ural Branch, Russian Academy of Sciences using JEM-200 CX (maximum accelerating voltage of $200 \mathrm{kV}$ ) and CM-30 transmission electron microscopes and Quanta 200 scanning electron microscope (maximum accelerating voltage of up to $30 \mathrm{kV}$ ), which was equipped with EDS and EBSD systems. Electron-microscopic transmission studies were performed using bright- and dark-field regimes. To identify phases, we analyzed selected area electron diffraction (SAED) patterns. Electrical resistivity $\rho(T)$ was measured by potentiometry using a double bridge in the temperature range 100-1170 K.

\section{Results and Discussion}

In accordance with the transition temperatures determined from the resistivity curves $\rho(T)$, a diagram of martensitic transformations was constructed (shown in Fig. 1). This diagram shows the temperature and concentration dependences of martensitic transformations of alloys, as well as atomic ordering B2 $\leftrightarrow L 2_{1}$ of austenitic phases and magnetic transitions from a paramagnetic state to antiferro- and ferromagnetic. The 
phase composition of the alloys was determined by the X-ray method and from selected electron diffraction patterns [1-14].

In accordance with the presented diagram, it follows that at room temperature the structure of martensitic phases changes with increasing aluminum content in the following sequence: a crystal lattice of type $\mathrm{L} 1_{0}(2 \mathrm{M}), 14 \mathrm{M}$ and $10 \mathrm{M}$.

The results of the microhardness measurements of the alloys are given in Table. Doping with aluminum in the range from 0 to 18 at. \% reduces the resistance of martensite to the hardness tester indenter. It can be concluded that, being in a martensitic state $2 \mathrm{M}$ and 14M with lower elastic moduli, these alloys have a lower hardness. Increase of microhardness in alloys with 20 and 22 at. \% Al can be associated, first, with a further change in the type of the crystal structure of martensite from $14 \mathrm{M}$ to $10 \mathrm{M}$. But, most likely, this fact correlates with the fact that the critical temperatures in these alloys are close to room temperature, at which microhardness measurements were carried out. Therefore, an increase of microhardness in alloys with 20 and 22 at. \% Al may be due to the presence of two-phase $(B 2+10 \mathrm{M})$, induced and due to deformation in the testing of hardness, providing additional hardening of the alloys. In austenitic alloys with 24 and 25 at. \% Al superstructural atomic ordering occurs from B2 and $L 2_{1}$ and the microhardness decreases again slightly.

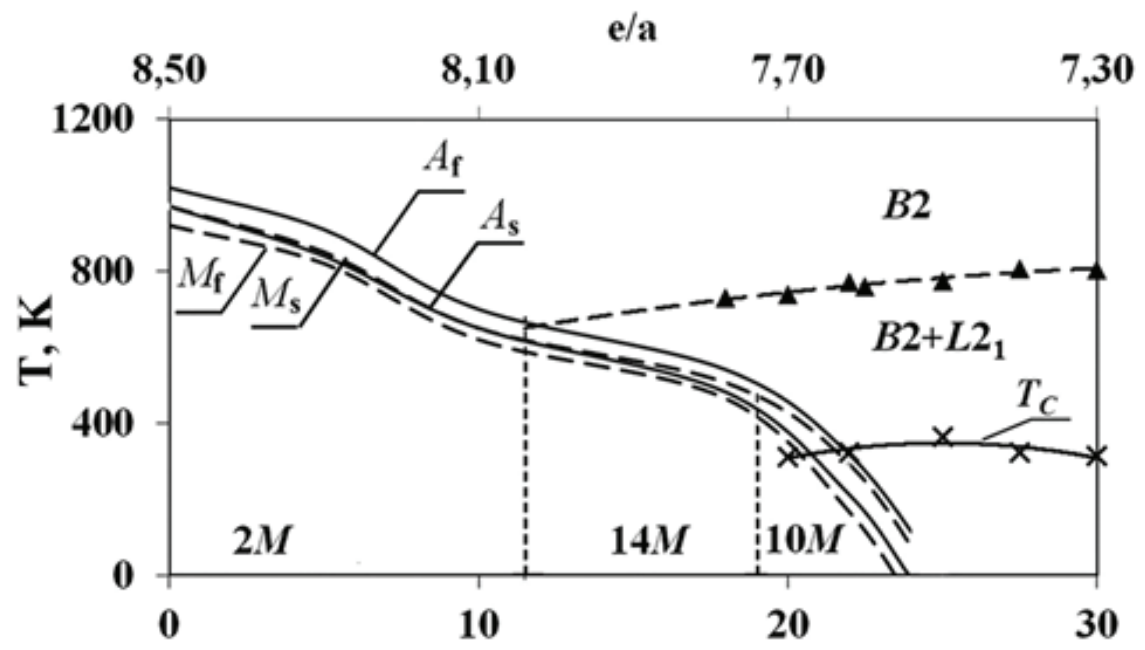

Al, at. $\%$

Figure 1: Phase diagram of martensitic transformations of $\mathrm{Ni}_{50} \mathrm{Mn}_{50-y} \mathrm{Al}_{y}$ alloys of the quasi-binary system $\mathrm{NiMn}-\mathrm{NiAl}$.

TABLE 1: The dependence of microhardness on the chemical composition.

\begin{tabular}{|l|c|c|c|c|c|c|}
\hline X, at. \% Al & 0 & 10 & 18 & 20 & 22 & 25 \\
\hline HV, ГПа & 4,30 & 3,52 & 2,90 & 3,79 & 3,79 & 3,10 \\
\hline
\end{tabular}


A fractography of the alloys was carried out using SEM in the secondary electron mode after bending tests of samples in order to determine the nature of the fracture. In fig. 2, a, b shows the image of the fractures of the studied alloys. Fractographic studies have shown that their destruction occurs both by means of the transcrystalline (along the grain boundaries) and intercrystalline types (mainly along the joints of the packets of martensitic crystals inside the grain). Obviously, the brittle destruction occurs along the grain (Fig. 2, a). Intercrystalline destruction occurrs by brittle and brittle-ductile types, which probably depends on the location of the packages of martensitic plates relative to the direction of the fracture crack. If the crack expends along the flat boundary of the package, then brittle fracture occurs. This behavior can be explained by the concentration of the strains and stresses near the boundaries packages caused by the realization of the TMTs in certain regions of the polycrystalline alloy. If the crack develops at an angle to the martensitic plates, then in such areas the fracture has a ductile or brittle-ductile nature (Fig. 2, b).
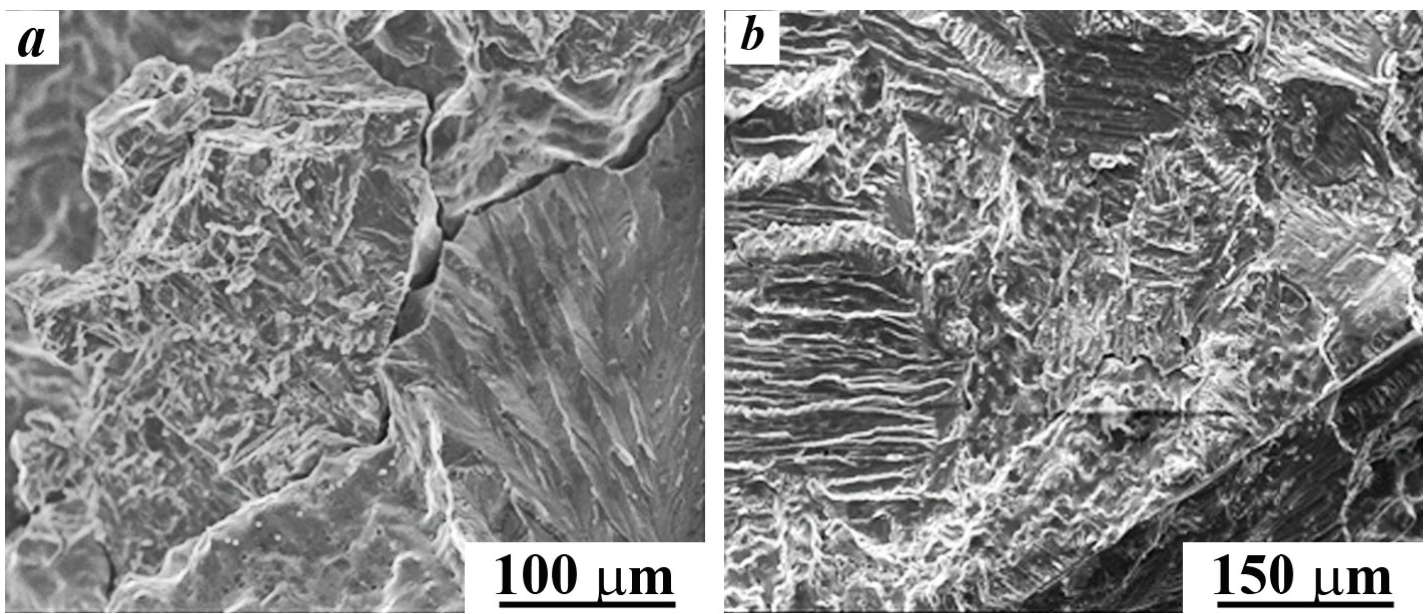

Figure 2: Fractographic studies of alloys: $\mathrm{a}-\mathrm{Ni}_{50} \mathrm{Mn}_{32} \mathrm{Al}_{18} ; \mathrm{b}-\mathrm{Ni}_{50} \mathrm{Mn}_{30} \mathrm{Al}_{20}$.

The thin structure of these alloys was studied by TEM. Fig. 3 shows TEM images of the martensite in the $\mathrm{Ni}_{50} \mathrm{Mn}_{32} \mathrm{Al}_{18}$ alloy $(\mathrm{a}, \mathrm{b})$ and the corresponding selected area electron diffraction (SAED) patterns (c). It allows to identify a seven-layer crystal lattice corresponding to the $14 \mathrm{M}$ crystal lattice. The substructure is represented by thin plates of the martensitic phase. The boundaries of the packets of martensitic plates are runoffs of grain-boundary misfit dislocations.

TEM studies were also carried out on alloys doped with 22 and 25 at\% Al. They showed that $\mathrm{Ni}_{50} \mathrm{Mn}_{28} \mathrm{Al}_{22}$ alloy is in single-phase austenitic state $\mathrm{B} 2$ (or L2 $2_{1}$ ). This is evidenced not only by dark-field and bright-field images of the tweed structure (Fig. 4 a, b), but also the analysis of SAED patterns (Fig. 4 c, d, e) and X-ray data. The analysis 
showed that the diffuse scattering bands, which are more intense near the reflections, are traces of the intersection of the Ewald sphere by flat scattering layers along the $\{111\}^{*}$ of reciprocal lattice, passing through its nodes, with the exception of 000 . The strongest scattering is concentrated along the $\langle 110\rangle^{*}$ and $\left.<112\right\rangle^{*}$.

The regular nature of diffuse scattering and tweed contrast is due to the presence of localized cooperative, mainly shear, atomic displacements in crystals [4]. Flat scattering layers over $\{111\}^{*}$ are interpreted in elastic-soft low-modulus crystals as a result of destabilization with respect to local displacements of close-packed atomic chains by $<111>$ and their shear correlations over close-packed $\{110\}$ type planes. These phenomena indicate that the alloy under study was in the pretransition B2 state $[4,5]$.
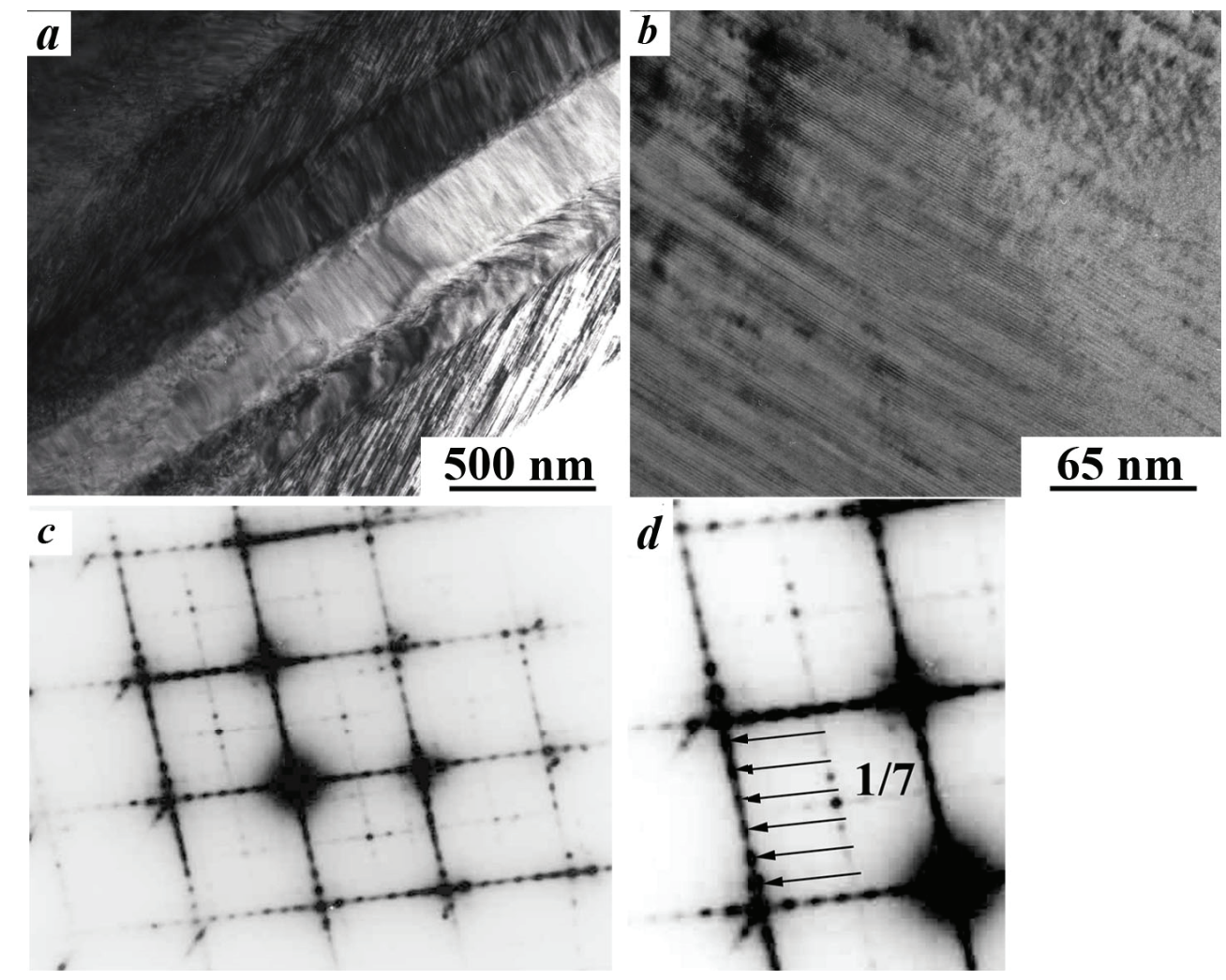

Figure 3: Bright-field TEM images of the $14 \mathrm{M}$ - martensite structure in the $\mathrm{Ni}_{50} \mathrm{Mn}_{32} \mathrm{Al}_{18}$ alloy (a, b), typical SAED of the alloy (c), enlarged fragment of the SAED pattern (d).

The crystal lattice of the $\mathrm{Ni}_{50} \mathrm{Mn}_{25} \mathrm{Al}_{25}$ alloy, according to $\mathrm{X}$-ray analysis, is ordered by type $L 2_{1}$. The SAED patterns presented in Fig. 5, c, $d$ show diffraction patterns that are identical to B2 or $\mathrm{L} 2{ }_{1}$ phase diffractions. They clearly show diffuse effects in the form of band and satellites. In addition, the grain structure of the alloy has tweed diffraction contrast (Fig. 5, a, b). These effects indicate the pretransition state of the alloy. 

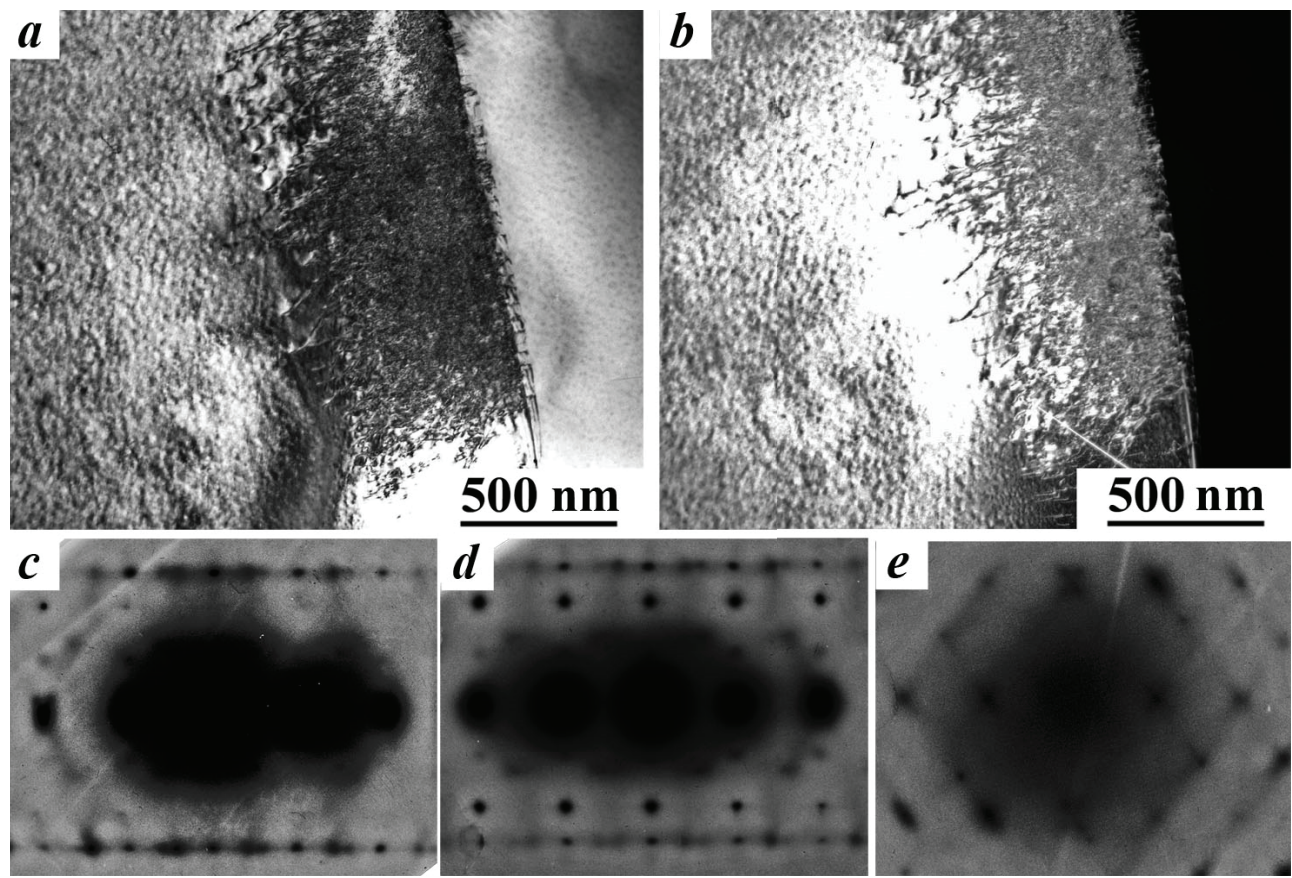

Figure 4: Bright-field (a), dark field (b) microstructure images and SAED patterns (c - e) of B2-austenite of $\mathrm{Ni}_{50} \mathrm{Mn}_{28} \mathrm{Al}_{22}$ alloy.

\section{Summary}

1. It is shown that with increasing in the aluminum content in alloys of the NiMn$\mathrm{NiAl}$ quasi-binary system, the critical temperatures of the thermoelastic martensitic transformations decrease and the martensite crystal lattice changes in the sequence $2 \mathrm{M}-14 \mathrm{M}-10 \mathrm{M}$.

2. The microhardness of the studied alloys naturally changes depending on the chemical composition and structural type of the resulting martensite with a specific thin substructure and morphology of martensitic crystals.

3. Destruction in the studied alloys occurs by transcrystalline and intercrystalline types. In alloys, brittle transcrystalline fracture cracks expend both along grain boundaries and along flat boundaries of martensite plate packs; intercrystalline brittle-ductile fracture occurs when cracks expand along shear systems at an angle to the habit of martensitic plates.

4. As shown by TEM and SEM, martensite has a predominant morphology in the form of a hierarchy of packages of lamellar and internally finely twinned coherent crystals with flat habit boundaries close to $\{110\}_{B 2}$. The systems of twinning shear for all types of martensite are close to the soft mode $\{101\}<10 \overline{1}>_{B 2}$ of B2 austenite. 

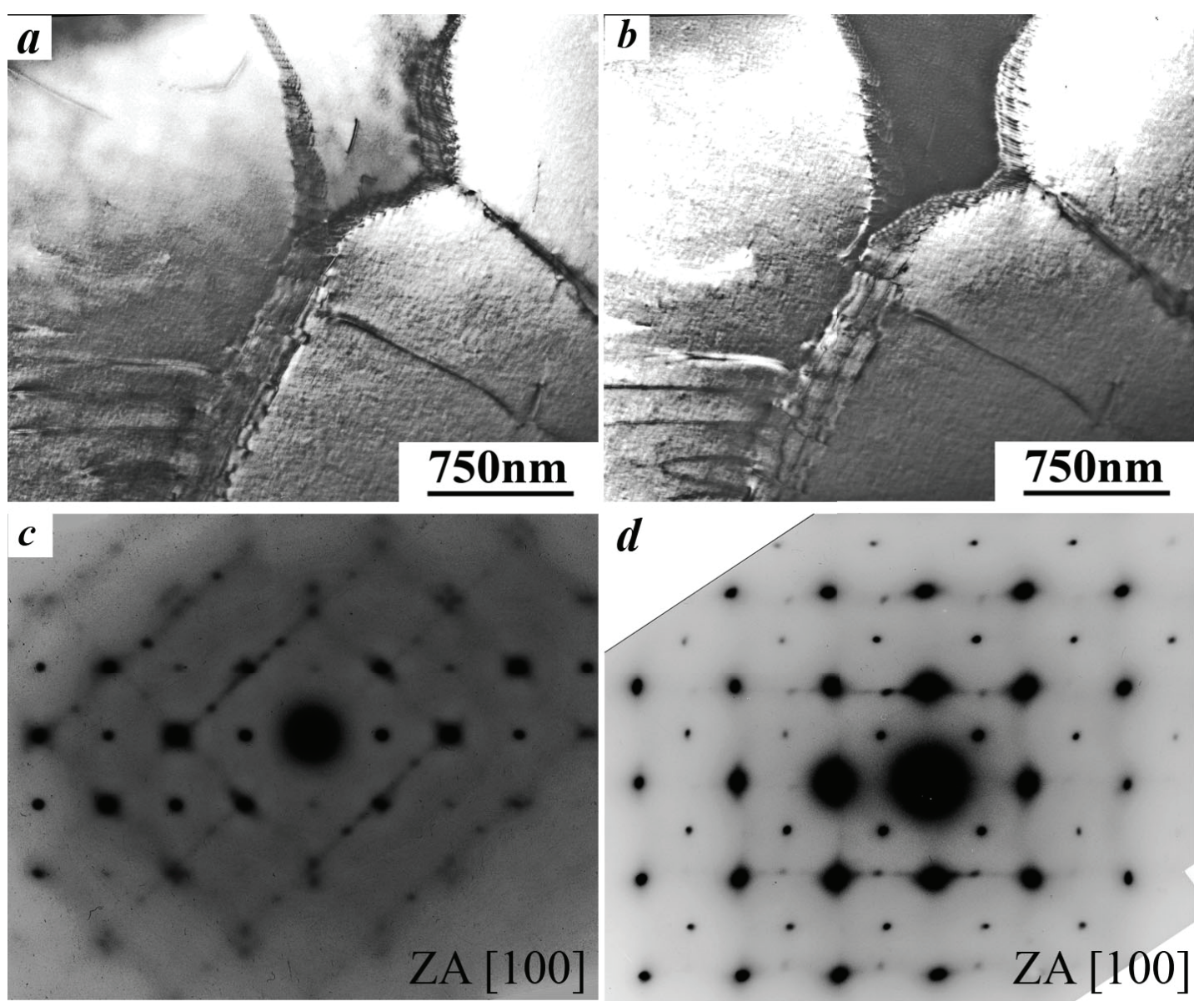

Figure 5: Bright-field (a), dark-field (b) images of the microstructure and SAED patterns of the L21-austenite (c, d) of the $\mathrm{Ni}_{50} \mathrm{Mn}_{25} \mathrm{Al}_{25}$ alloy.

5. It was found that in the premartensitic state, the austenite of the studied alloys can be described by short-range atomic displacements of the type of future martensitic phase mainly by correlated and lateral displacements along the $\{101\}<101>$ ${ }_{b c c}$ system with the formation of nano-localized structures of the intermediate type.

\section{Acknowledgment}

The work was carried out within the framework of the state task of Russian Ministry of Education and Science (cipher "Structure", No. AAAA-A18-118020190116-6) and with partial support of the RFBR (project No. 18-32-00529 mol_a).

\section{References}

[1] V.G. Pushin, E.S. Belosludtseva, V.A. Kazantsev, N.I. Kourov, Features of Martensitic Transformation and Fine Structure of Intermetallic Compound $\mathrm{Ni}_{50} \mathrm{Mn}_{50}$, Inorganic 
Materials: Applied Research. 4 (4) (2013). 340-347

[2] V.G. Pushin, N.N. Kuranova, E.B. Marchenkova, E.S. Belosludtseva, V.A. Kazantsev, N.I. Kourov. High-Temperature shape memory effect and the B2-L1 $1_{0}$ thermoelastic martensitic transformation in Ni-Mn intermetallics, Technical Phisics. 58 (2013) 878 887.

[3] Pre-transition phenomena and martensitic transformations, V.G. Pushin, V.V. Kondrat'ev, Physics of Metals and Metallography. 78 (5) (1994) 40-61.

[4] V.G. Pushin, S.D. Prokoshkin, R.Z. Valiev et all, Alloys of nickel titanium with shape memory. Part 1 Structure, phase transformations and properties, ed. by V.G. Pushin, UB of RAS, Ekaterinburg, 2006 - pp. 438.

[5] E.S. Belosludtseva, N. N. Kuranova, N. I. Kourov, V. G. Pushin, V. Yu. Stukalov, A. N. Uksusnikov, Effect of Aluminum Alloying on the Structure, the Phase Composition, and the Thermoelastic Martensitic Transformations in Ternary Ni-Mn-Al Alloys, Technical Physics. 60 (2015) 1000-1004.

[6] A.V. Lukyanov, V.G. Pushin, N.N. Kuranova, A.E. Svirid, A.N. Uksusnikov, Yu.M. Ustyugov, D. V. Gunderov, Effect of the Thermomechanical Treatment on Structural and Phase Transformations in Cu-14Al-3Ni Shape Memory Alloy Subjected to HighPressure Torsion, Physics of Metals and Metallography. 119 (2018) 374-383.

[7] V.G. Pushin, N.N. Kuranova, E.B. Marchenkova, E.S. Belosludtseva et. all, Thermoelastic Martensitic Transitions and Shape Memory Effects: Classification, Crystal and Structural Mechanisms of Transformations, Properties, Production and Application of Promising Alloys, in: V.V. Rubanik, N.N. Resnina (Eds.), Shape memory alloys: properties, technologies, opportunities, Trans. Tech. Publication, Switzeland, 2015.33 pp. 978-3-03835-357-7

[8] E.S. Belosludtseva, N.N. Kuranova, E.B. Marchenkova, V.G. Pushin, Features of thermoelastic martensitic, structure and properties in ternary B2-alloys based on $\mathrm{NiMn}$ - NiTi, NiMn - NiAl, NiMn - NiGa, Ni2MnGa - Ni3Ga quasi-binary systems, Materials Today: Proceedings. 4 (2017) 4717-4721

[9] E.S. Belosludtseva, V.G. Pushin, E.B. Marchenkova, A.E. Svirid, A.V. Pushin, Investigation of Intermetallic Alloys Based on Ni-Mn with Controlled Shape Memory Effect Materials, Research Proceedings 9 (2018) 14-18.

[10] V.G. Pushin, E.S. Belosludtseva, E.B. Marchenkova, Multicomponent Metallic NiMn-Based Alloys with Thermally, Mechanically and Magnetically Controlled Shape Memory Effects, Physics of Metals and Metallography. 119 No. 12 (2018) 1191-1195.

[11] A.E. Svirid, V.G. Pushin, N.N. Kuranova, A.V. Luk'yanov, A.V. Pushin, A.N. Uksusnikov, Y.M. Ustyugov, The structure-phase transformations and mechanical properties of 
the shape memory effect alloys based on the system $\mathrm{Cu}-\mathrm{Al}-\mathrm{Ni}$, Materials Today: Proceedings 4 (2017) $4758-4762$.

[12] A. V. Lukyanov, V. G. Pushin, N. N. Kuranova, A. E. Svirid, A. N. Uksusnikov, Yu. M. Ustyugov, D. V. Gunderov, Effect of the thermomechanical treatment on structural and phase transformations in Cu-14Al-3Ni shape memory alloy subjected to high pressure torsion, Physics of Metals and Metallography. 119 (2018) 374-383.

[13] A.V. Lukyanov, A.E. Svirid, A N. Uksusnikov, The effect of high-temperature thermomechanical processing and severe plastic torsional deformation on the structuralphase transformations and properties of Cu-Al-Ni alloys with shape memory effect, in V.V. Klubovich (Eds) Monograph, Belarus, Vitebsk "VSTU", 2017 - 467 p.

[14] A.E. Svirid, N.N. Kuranova, A.V. Lukyanov, V.V. Makarov, N.V. Nikolayeva, V.G. Pushin, A.N. Uksusnikov, The influence of thermomechanical processing on the structurephase transformations and mechanical properties of Cu-Al-Ni alloys with shape memory, Russian Physics Journal. in the press. 